\title{
Conceptualization and implementation of a regional groundwater model for the Neckar catchment in the framework of an integrated regional model
}

\author{
J. Jagelke and R. Barthel \\ Institute of Hydraulic Engineering, Universitaet Stuttgart, Germany \\ Received: 7 January 2005 - Revised: 1 August 2005 - Accepted: 1 September 2005 - Published: 16 December 2005
}

\begin{abstract}
Joint modelling of surface and subsurface systems is necessary to assess the quantity and quality of the water resources in a watershed. Therefore, it is widely applied in integrated regional models.

The presented study deals with groundwater modelling within the framework of the integrated regional model MOSDEW, which is being developed for the Neckar catchment in Germany with the objective of contributing to the implementation of the EU Water Framework Directive (EU-WFD) (www.rivertwin.org). The groundwater model aims at obtaining a better understanding of the groundwater recharge processes and at evaluating the groundwater resources on watershed scale. In this paper the developed coupling method is described. Furthermore the groundwater model construction based on the available database and first calibration results are presented.
\end{abstract}

\section{Introduction}

The objective of the EU-Research project RIVERTWIN is the development of an integrated regional model MOSDEW for the strategic planning of water resources in twinned river basins under contrasting ecological, social and economic conditions. The basins under examination are the Neckar catchment in Germany, the Ouémé basin in Bénin and the Chirchik basin in Uzbekistan. Due to the higher data density in Germany, the integrated model is first being developed for the Neckar catchment. Upon completion, it will afterwards be adjusted to the remaining two catchments, for which only sparse data is available. Therefore, only the Neckar catchment is discussed in this paper.

The concept of the integrated model is shown in Fig. 1. The model consists of eight sub-models which evaluate the current status of and simulate future development within the three fields economy, land use and water resources. The sub-

Correspondence to: J. Jagelke

(johanna.jagelke@iws.uni-stuttgart.de) models interact with each other through the exchange of defined parameters (see Fig. 1).

Figure 2 shows the coupling principle for water resources modelling with regard to the water quantity. The groundwater model interacts with the rainfall-runoff model HBV and with the water-demand model WEAP. The groundwater model receives the spatially and temporally highly differentiated groundwater recharge from the HBV-model and water extractions on municipality scale from the WEAP-model. Using this data as the boundary conditions, the groundwater model simulates the base flow and provides it to the flood routing module of the HBV-model. The coupled solution of the models - including calibration and validation - is based on the sequential solving of equations for the common parameters until the difference between succeeding solutions of the common parameter becomes less than a predefined tolerance. Details regarding the functioning of the HBV-model and on the calibration of the groundwater recharge are given in Götzinger and Bárdossy (2005).

\section{Neckar catchment}

The Neckar catchment is located in the state of BadenWürttemberg in the southwestern part of Germany. It covers an area of almost $14000 \mathrm{~km}^{2}$ with a population of 5 million people. The terrain elevation varies between 89.9 and $974.6 \mathrm{~m}$ above sea level.

The climate in the Neckar catchment is moderate. Due to the heterogeneity of the relief, rainfall and evaporation vary strongly. The rainfall ranges between less than 800 and $2000 \mathrm{~mm} / \mathrm{a}$, the average evapotranspiration is $550 \mathrm{~mm} / \mathrm{a}$. Although the maximum rainfall occurs during summer, summer evaporation rates are also high and the groundwater recharge takes place mainly during the winter. According to model calculations for the period from 1980 to 2002, the mean groundwater recharge is $158 \mathrm{~mm} / \mathrm{a}$; it varies spatially from 3 to $643 \mathrm{~mm} / \mathrm{a}$ (Armbruster, 2002). 


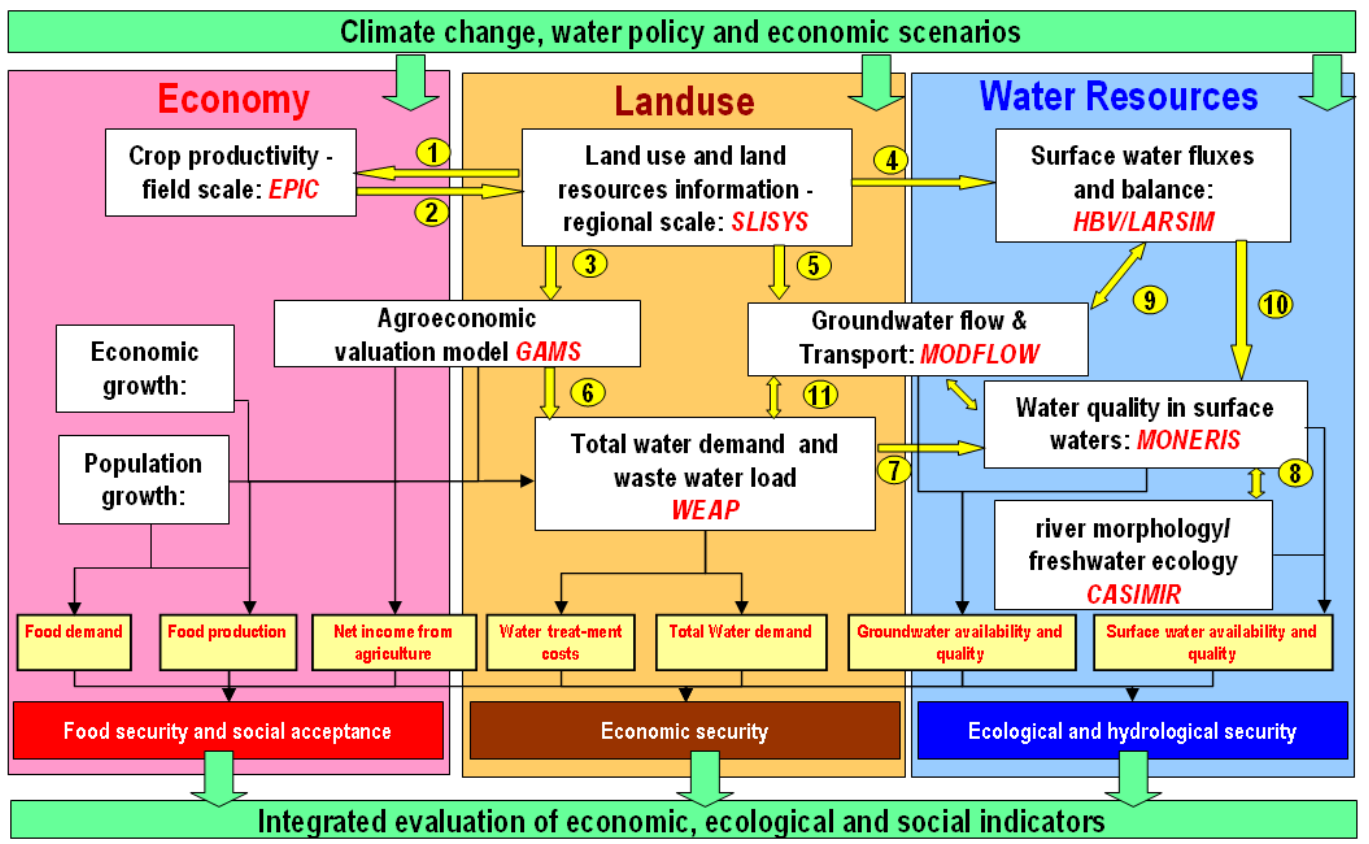

Exchange Parameters: 1: Soil, terrain, climate and vegetation information; 2: yield, biomass,water and nutrient balance and transport, water consumption, pesticide load; 3: yield, biomass, water and nutrient demand; 4: Surface water, Sediment, pesticide and nutrient loss; 5: Recharge, load; 6: Water demand from agriculture; 7: Reflux treated water and load; 8: Sediment and nutrient load; 9: Groundwater Surface Water interaction; 10: water flux in river network; 11: water availability in rivers, lakes and aquifers

Fig. 1. Schematized concept of the integrated model MOSDEW showing the single sub-models and the corresponding exchange parameters.

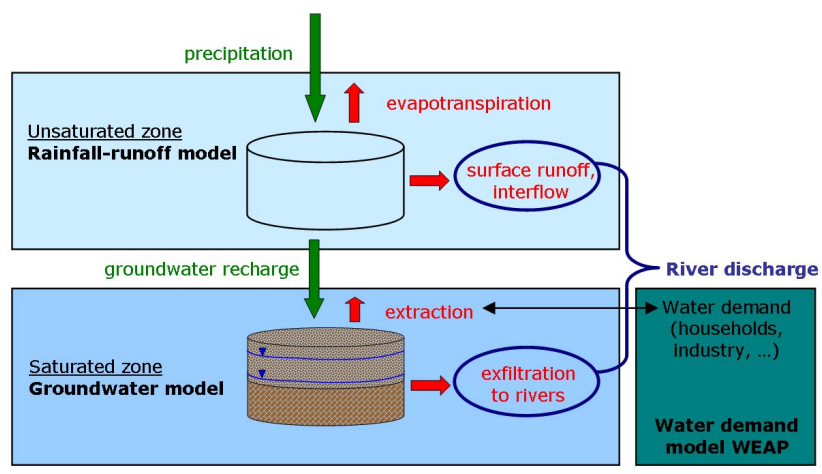

Fig. 2. Coupled water resource model.

The hydrogeological situation is dominated by the occurrence of fractured and karst formations. Ten quasi-horizontal hydrogeological units can be distinguished which comprise eight main freshwater aquifers. Figure 3 shows the outcrop of the hydrogeological units. The layers dip slightly to the southeast.

Most of the hydrogeological units are composed of sandstone or limestone. Formations rich in rock salt and gypsum occur at distinct positions in the hydro-stratigraphic sequence in regionally varying thickness. The hydraulic properties of the fractured or karst aquifers vary strongly in space. The aquifers are mostly confined. The occurrence of saline and karstic formations makes the assessment of the groundwater resources in the Neckar catchment a very challenging task. Both horizontal as well as vertical flows have to be considered in order to evaluate the available amount of groundwater of good quality in space and time.

\section{Groundwater model}

\subsection{Model selection}

In integrated regional models, hydrological models are usually applied. Distributed models are rarely used on the regional scale due to the required data density for parameterisation and to their high computational demand (Wolf et al., 2004). Yet simple hydrological models are unable to simulate fluctuations of the piezometric heads, flow direction and velocity, cross formational flow, etc. Therefore a distributed model was chosen to reproduce the complex groundwater system. In view of the complex hydrogeological situation, it was decided to construct a three-dimensional model consisting of ten layers.

The 3-D Modular Finite Difference Groundwater Flow Package MODFLOW (McDonald and Harbaugh, 1988) was selected. It is based on the horizontal and vertical discretisation of the modelling domain and solves the groundwater flow equation for each cell of the model. MODFLOW allows 


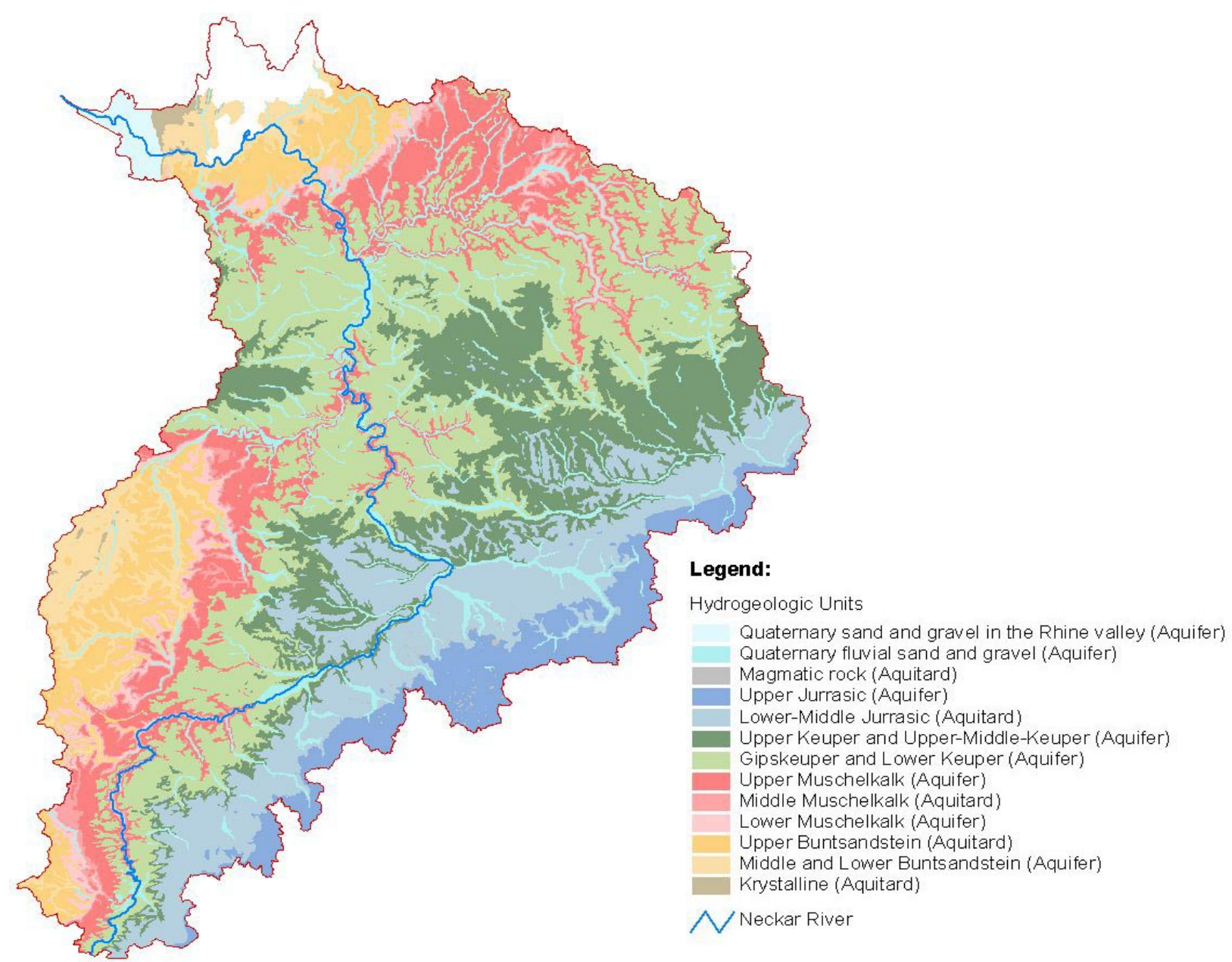

Fig. 3. Hydrogeological units in the Neckar basin (LGRB, 2000).

the simulation of the leakage between adjacent hydrogeological units and it can reproduce flowpaths in all three spatial directions. Both features can help in quantifying the freshwater resources. MODFLOW offers the additional benefits of being easy to explain and free of cost, rendering the anticipated transfer of modelling knowledge to Bénin and Uzbekistan feasible.

\subsection{Model discretisation}

The discretisation of the model domain is a fundamental task because it directly affects the results of the numerical model. In general the finer the discretisation, the more detailed and precise is the simulated groundwater flow, provided that data is available in sufficient quantity and quality. Despite the rapid development of processors in recent years, computing power remains a constraint for the discretisation of regional groundwater models. Far more important than the computation time itself is the time and effort necessary to set up and evaluate model runs for testing, calibrating and validating.

Since the project RIVERTWIN is carried out with support of the environmental authorities of the State of Baden-
Württemberg, it was decided to utilise the modelling grid used by the authorities. This modelling grid is based on a $1 \mathrm{~km}^{2}$-raster which is aligned to north. The resulting number of modelling cells is 14000 per layer, which still assures a convenient computing time. Furthermore the $1 \mathrm{~km}^{2}$-grid is coarse enough to treat the fractured and karstic aquifers as continuous media. Under these conditions, the fractures can be assumed to be small compared to the extent of the model cell. Thus the application of MODFLOW, which is based on the Darcy equation, is justified.

However, the used $1 \mathrm{~km}^{2}$-grid is too coarse to produce accurate results on the local behaviour of the groundwater resources, e.g. to evaluate the drawdown at a single well. Since the groundwater flow model has to deliver solutions for regional problems such as regional changes in groundwater resources or base flow within regions bigger than one modelling cell, local problems play a minor role and can quite often be neglected. The grid resolution of $1 \mathrm{~km}^{2}$ can be considered appropriate for its application to the given regional modelling task. 


\section{Database}

In order to model a groundwater system, a conceptual hydrogeological model representing the groundwater flow system must be constructed using all available data, i.e. maps, profiles, and pumping tests. When establishing a conceptual model, the hydrogeological conditions have to be simplified so that they can be implemented in the numerical groundwater model. At the same time this "simplified groundwater system" should still represent the natural conditions in a reasonable way with respect to the applicability of the model results.

The following table gives an overview on the components of the conceptual model and the underlying data, respectively. Due to insufficient data availability, the datasets storage coefficients, leakage, as well as the hydraulic conductivity have to be at least partly assumed or estimated. In the following paragraph the components are introduced in detail.

\subsection{Aquifer geometry}

Based on all available data, a 3-D-hydrogeological model was established. This first conceptual model was a relatively complex representation of the hydrogeological situation, which had to be iteratively simplified and fitted to the modelling grid in order to be implemented in MODFLOW.

The hydrogeological model is based on the Hydrogelogical Units (LGRB, 2002), a compilation of hydrogeological data produced by the State Institute for Geology, Mining and Raw Materials (Landesanstalt für Geologie, Bergbau und Rohstoffe, LGRB) on behalf of the Ministry of the Environment and Communication of the State of BadenWürttemberg (UVM). Within the scope of this compilation, the outcrops of the seven main aquifers which occur in the state of Baden-Württemberg were delineated and the hydrogeological properties of the aquifers were characterized. The Hydrogeological Units correspond to the main water bodies according to the Water Framework Directive (WFD) of the European Union (EU).

In order to extend the 2-D-distribution of the hydrogeological units at the surface supplied by the LGRB downward, additional information on the stratigraphical sequence has been collected in the course of the given project. The following sources were used:

1. digital contour maps of stratigraphical boundaries contained in the Hydrogeological Units,

2. analogue structural maps included in the Geological Map for the State of Baden-Württemberg on the scale of 1:25000,

3. analogue structural maps found in literature.

All available analogue structural maps were collected, scanned, and georeferenced and the elevations of contour and structure lines (i.e. fractures) were digitized. Different maps containing the same elevation information were compiled and contour lines crossing map edges were adjusted.
Since the elevation map compilation contains interruptions, an interpolation was necessary in order to obtain a consistent elevation map of the tops and the bottoms of all modelled hydrogeological layers covering the entire Neckar basin. The interpolation method used was the deterministic fast Inverse Distance Weighted method.

In order to implement the layered structures in the MODFLOW numerical model, the elevation values were aggregated for each cell of the modelling grid, whereby the elevations were adjusted starting from the top (the elevation model), so that the layers do not intersect and a minimum layer thickness of $5 \mathrm{~m}$ is maintained.

\subsection{Hydraulic properties}

The available hydraulic properties of the eight model layers are described in the Hydrogeological Units (LGRB, 2002). In this framework, more than 2000 available pumping tests carried out in the state of Baden-Württemberg were statistically evaluated. The statistical results give an overview of the magnitude and the variation of the transmissivities and the hydraulic conductivities in the different hydrogeological units (LGRB, 2002).

Despite the fact that this is the largest available dataset of hydraulic properties, it provides only general information on the hydrogeological units and does not reveal the information needed to assign parameters to each of the 14000 modelling cells. Therefore, the effective parameters are to be estimated using an inverse modelling approach based on the Gauss-Marquardt-Levenberg method (Sect. 5).

\subsection{Boundary conditions}

In a large river catchment such as the Neckar basin, it can be assumed that the surface watershed has the same extent as the subsurface groundwater catchment. Therefore no-flow boundaries were assigned all around the model domain. Several previously carried out tracer tests support this assumption.

Inside the model domain, rivers and groundwater extraction from wells are assigned as boundary conditions. River levels needed to calculate the exchange rates between the rivers and adjacent aquifers will be calculated by partner models in the MOSDEW modelling framework. Determining the groundwater extraction rates for each individual well in the model domain was an especially difficult task because of the complex hierarchical system of responsibilities in the Water Resources Sector. The Lower Water Authorities (Untere Wasserbehörden) are located on the district level (Landkreise) and they are generally in charge of the water rights, comprising all issues of water extraction. Since an extraction fee has to be paid, the Lower Water Authorities collect information about the amount of extracted groundwater. Within the Neckar catchment there are 28 Lower Water Authorities. Because there are no standards regarding data collection, some of the 28 districts collect monthly extraction data, whereas others collect annual values. In addition, not all of 
Table 1. Conceptual model components and the data basis.

\begin{tabular}{|c|c|c|}
\hline & Data set & Data source \\
\hline \multirow{3}{*}{ Aquifer Geometry } & Digital elevation model & LfU \\
\hline & Horizontal extent of the hydrogeological units & LGRB 2002 \\
\hline & Vertical extent of the hydrogeological units & Diverse literature \\
\hline \multirow{3}{*}{ Hydraulic Properties } & Hydraulic conductivity/transmissivity & LGRB 2002 \\
\hline & Storage coefficient & Diverse Literature \\
\hline & Leakage & Diverse Literature \\
\hline Initial Condition & Water head & LGRB, LfU \\
\hline Boundary Conditions & Groundwater extraction & Lower Water Authorities \\
\hline
\end{tabular}

the data is available in digital format. The greatest inconvenience is that some districts have no geographical information for the extraction sites.

All 28 Lower Water Authorities in the Neckar catchment have agreed to make the extraction data available. Nevertheless data processing is very time-consuming because some data has to be digitized or linked to the extraction sites.

\subsection{Initial conditions}

In order to determine the initial groundwater heads to be used as starting conditions in the flow model, groundwater level data for the entire Neckar catchment is needed. The State Institute for Environmental Protection Baden-Württemberg (LfU) delivered a groundwater database containing time series composed of groundwater levels measured weekly from 1980 up to 2003 at 194 measuring points. Furthermore the State Geological Survey (LGRB) supplied 800 individual groundwater measurements carried out in connection with pumping tests. Additionally groundwater level data from the area surrounding of the Neckar catchment was supplied by the LfU.

The groundwater measurement points are irregularly distributed. Many wells are situated in the Quaternary river sediments - especially in the Rhine Valley - or in the deeper fractured aquifers along the main rivers. Because data is very sparse between the main river valleys, methods other than simple interpolation had to be applied in order to construct the piezometric surface. Therefore, a kriging interpolation was carried out using all available groundwater measurements as well as the following additional data:

1. Surface elevation along rivers of first and second stream order which was assumed to be equivalent to the piezometric surface,

2. Estimated groundwater elevation along the mountain ranges between the main river valleys based on a correlation between groundwater measurements and the surface elevation.

Figure 4 shows the interpolated groundwater table.

\section{Model calibration}

The model calibration was first carried out for steady-state flow conditions. Thereby the hydraulic conductivity of preassigned geological zones was adjusted applying the GaussMarquardt-Levenberg algorithm such that the weighted sum of the squared differences between the measured and the model-generated groundwater levels is minimized. The following figures show the first calibration results.

Both the groundwater table in Fig. 4 as well as the statistics in Fig. 5 display a satisfactory calibration result with a plausible groundwater flow field and a relatively small error: the root mean squared error is $35 \mathrm{~m}$ and the correlation coefficient is 0.97 . This is a good basis for the transient calibration.

\section{Discussion}

As has become apparent in the previous chapters, this work is at an early stage. At present, the focus lies upon the compilation of the data to build the hydrogeological conceptual model. This paper therefore only provides very basic considerations on data availability and its impact on the modelling strategy. Yet this work may be of interest to a broader public in the groundwater modelling and water management community, as regional, catchment-wide, distributed, three-dimensional groundwater flow models are not yet common. Usually hydrological models are applied on such a scale. Hydrological models usually allow the estimation of (ground) water balances but not the evaluation of groundwater heads, flow regimes and other important parameters needed in water management systems. The implementation of the EU-WFD requires the application of models that can answer questions regarding the good status of the quantity and quality of groundwater resources. Since this need arises more and more in many catchments, it seems beneficial to point out that planning and designing a large scale groundwater flow model in a geologically heterogeneous region is completely different from developing a common small-scale model for a specific purpose. Data availability, complexity of the model domain, purpose and aim of the model, integration into interdisciplinary frameworks and finally the 


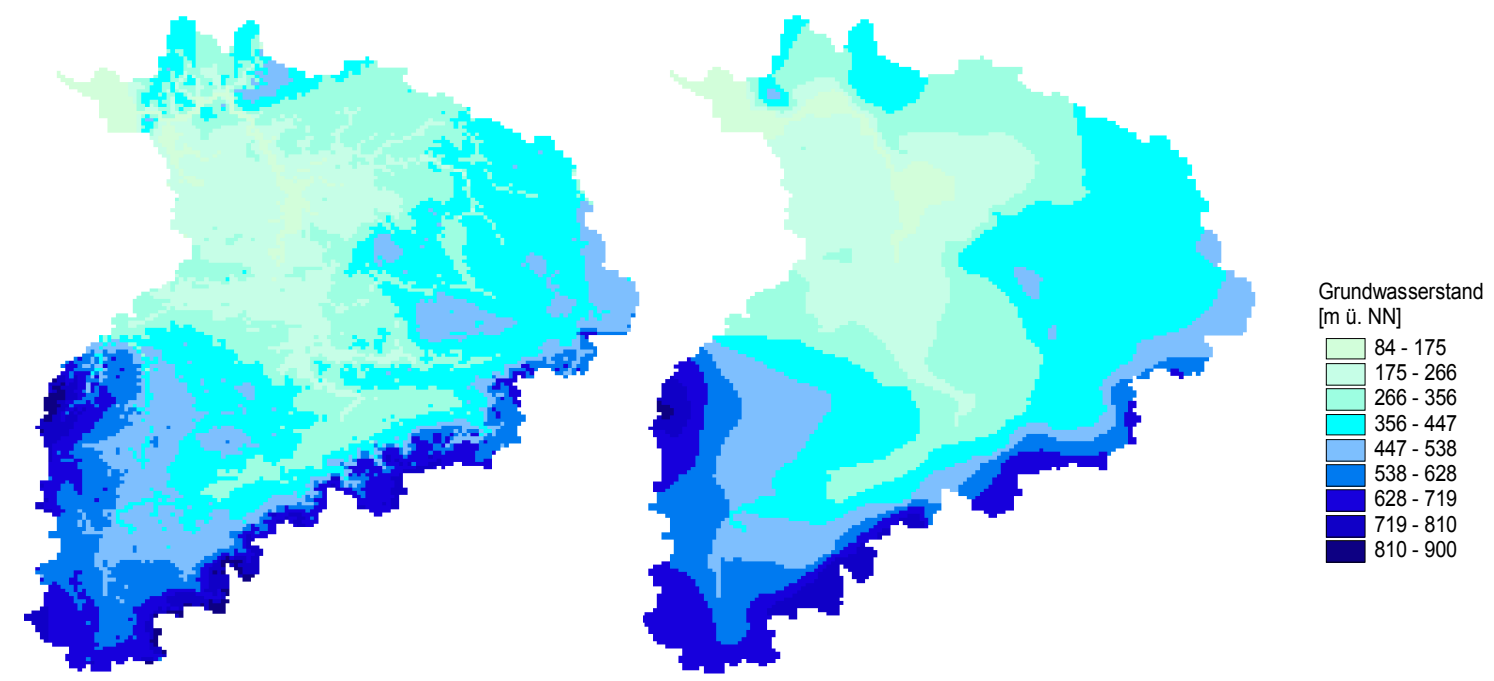

Fig. 4. Interpolated groundwater table (left) and model-generated groundwater table from the steady-state calibration (right).

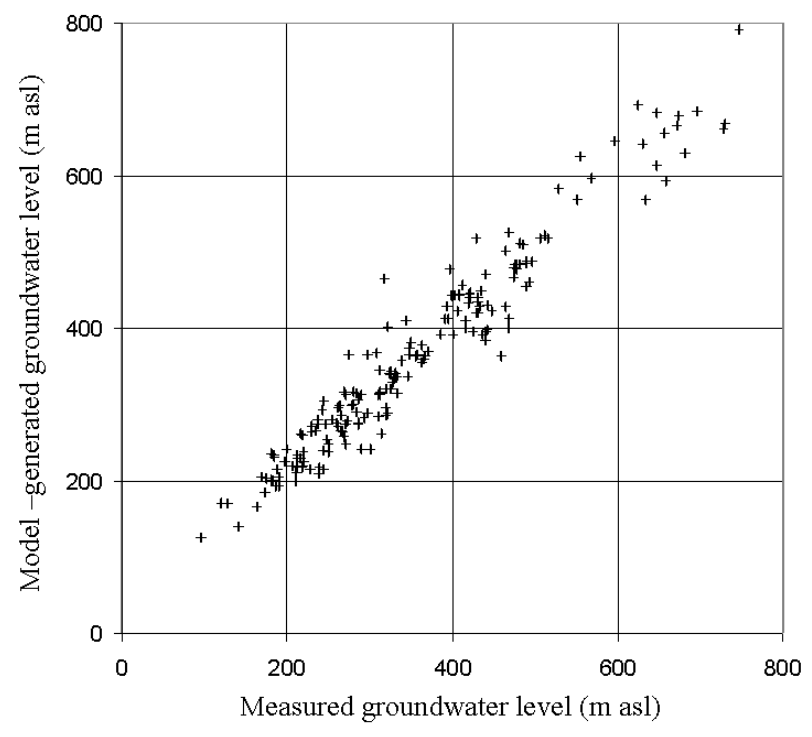

Fig. 5. Comparison of measured and model-generated groundwater levels.

applicability have to be considered carefully. To find the right balance is the critical task. In the present study the following aspects concerning the data situation were found to be decisive. Whereas in some cases they reflect at least partly the situation in Germany, most aspects can be generalized:

The data compilation in regional groundwater modelling is very time consuming because many competent authorities exist on this spatial level and their responsibilities often overlap. Therefore, data requests have to be addressed to several offices. Because of coexisting responsibilities, the collected data is often not consistent and the data processing therefore laborious.

Also problematic are a) the total amount of available data, which is generally small and b) the irregular distribution of the available data. The model strategy and discretisation has to find a balance between those areas where data is very scarce and those areas where the data density is very high. To achieve globally reliable and applicable results means finding compromises for both cases.

In spite of the very good data situation in the Neckar catchment, there are still significant gaps which must be bridged by interpolation or assumptions based in part on educated guesses. The need to interpolate data is not exceptional in groundwater modelling, but in a regional model the results of interpolation are even less reliable because of the large distances between observation points. Often the most basic requirements needed to interpolate meaningfully between two data points are not fulfilled. On the other hand, for some parameters, interpolation is the only way to parameterize the large number of cells.

Whereas interpolation and the subsequent uncertainty are common for less investigated areas (usually large), a high data density and therefore the need to aggregate and average exists in few well studied regions, namely the vicinity of large cities and the river valleys. Here far more information is available, but the averaging of data to find effective parameters for large model cells (here $1 \mathrm{~km}^{2}$ ) results in a loss of detail and accuracy. Local refinements, nested models or advanced discretisation methods are usually not an option in integrated regional modelling on the catchment scale. Here the uncertainty of model results will be lower but less accurate than possible.

In general, regional groundwater flow models on the catchment scale almost always comprise geologically and geomorphologically different zones and always have a varying, scarce data situation. The effort needed to gather and compile the data is significant and should not be underestimated. Given those facts it is obvious that regional models can only be used for certain purposes, and that those are different from the purposes for which typical "normal scale" groundwater flow models are used. The bottom line is that regional models can only provide results which are valid on the regional scale. 
Edited by: P. Krause, K. Bongartz, and W.-A. Flügel

Reviewed by: anonymous referees

\section{References}

Armbruster, V.: Grundwasserneubildung in Baden-Württemberg, Freiburger Schriften zu Hydrologie, Band 17, Freiburg i. Br., 2002.

Götzinger, J. and Bárdossy, A.: Integration and Calibration of a conceptual Rainfall-Runoff-Model in the framework of a Decision Support System for River Basin Management, Poster Session, International Conference on Integrated Assessment of Water Resources and Global Change: A North-South Analysis (2325 Februar 2005, Universität Bonn), Zentrum für Entwicklungsforschung (ZEF), 2/2005.
LGRB: Hydrogeologische Einheiten in Baden-Württemberg, Freiburg, 2002.

McDonald, M. G. and Harbaugh, A. W.: A Modular ThreeDimensional Finite-Difference Ground-Water Flow Model: U.S. Geological Survey Techniques of Water-Resources Investigations, Book 6, Chap. A1, Washington, USA, 1988.

Wolf, J., Rojanschi, V., Barthel, R., and Braun, J.: Modellierung der Grundwasserströmung auf der Mesoskala in geologisch und geomorphologisch komplexen Einzugsgebieten, 7. Workshop zur großskaligen Modellierung in der Hydrologie, Neue methodische Ansätze zur Modellierung der Wasser- und Stoffumsätze in großen Einzugsgebieten, Kassel University Press GmbH, Kassel,2004. 